\title{
CHANGES IN THE SPATIAL PATTERN OF NET EARNINGS: EVIDENCE FROM SERBIA*
}

\author{
Uglješa STANKOV - Vanja DRAGIĆEVIĆ \\ (Received: 23 July 2013; revision received: 10 September 2013; \\ accepted:14 September 2014)
}

\begin{abstract}
Spatial autocorrelation analysis is an important method that can reveal the structure and patterns of economic spatial variables. It can be used to identify not only global spatial patterns in the country, but also characteristic locations at micro levels. In this research, we used spatial autocorrelation methodologies, including Global Moran's I and Local Getis-Ord Gi statistics to identify the intensity of the spatial clustering of municipalities in Serbia by the level of average monthly net earnings from 2001 to 2010. We identified and mapped local clusters (hot and cold spots) by the level of average monthly net earnings for the same period. The results show that overall spatial segregation between municipalities with high and low average monthly net earnings was predominantly increasing during the investigated period. Local statistics illustrated that overall spatial segregation followed a broad north-south divide, with a concentration of municipalities with high net earnings in the north of Serbia, and low net earnings in the south. Closer inspection showed that at the beginning of the study period, there were three statistically significant hot spots in the north. As time passed, only one highly clustered hot spot remained - the Belgrade region. One cold spot retained a relatively stable position in the country's southeast. This research shows that spatial changes of net earnings can be successfully studied with respect to statistically significant global and local spatial associations in the variables using spatial autocorrelation analysis.
\end{abstract}

Keywords: earnings inequality, spatial autocorrelation analysis, Serbia

JEL classification indices: C46, J31, O52, P2

* This paper is part of project No. 114-451-2644/2014-01 funded by the Provincial Secretariat for Science and Technological Development of the Vojvodina Province, Serbia.

Uglješa Stankov, corresponding author. Assistant Professor at the Department of Geography, Tourism and Hotel Management, Faculty of Sciences, University of Novi Sad, Serbia.

E-mail: ugljesa.stankov@dgt.uns.ac.rs

Vanja Dragićević, Assistant Professor at the Department of Geography, Tourism and Hotel Management, Faculty of Sciences, University of Novi Sad, Serbia.

E-mail: vanja.dragicevic@dgt.uns.ac.rs 


\section{INTRODUCTION}

In many spatial data applications, the variations at a location are highly influenced by the variation at neighbouring locations. A variable's natural inclination to exhibit similar values as a function of distance between the spatial locations at which it is being measured is known as spatial dependence, and spatial autocorrelation is used to measure this spatial dependence (Gangodagamage et al. 2008). Spatial autocorrelation is defined as the correlation of a variable with itself over space (Burt et al. 2009). Spatial autocorrelation is concerned with establishing whether the presence of a variable in one region makes the presence of that variable in neighbouring regions more or less likely (Thomas - Huggett 1980). Spatial autocorrelation can be positive and negative. If similar values (high, medium or low) of a variable tend to cluster in space, the geographical distribution of that variable can be described as positively spatially autocorrelated. Negative spatial autocorrelation exists when nearby variables are dissimilar (Burt et al. 2009). For example, many demographic and socio-economic variables (population density, house price, etc.) exhibit positive spatial autocorrelation because of the way phenomena are spatially organised.

Various authors used spatial autocorrelation analysis as an important method to reveal the structure and patterns of economic spatial variables. Rey - Montouri (1999) used a spatial econometric approach to analyse US regional income convergence; Patacchini - Rice (2007) identified and described the spatial structure of economic performance for Great Britain through the analysis of the patterns of spatial association for different indicators of economic performance, while Zierahn (2012) focused his research on the importance of spatial dependencies using spatial autocorrelation in order to analyse regional employment growth in Germany. Spatial autocorrelation is also used to identify spatial patterns of income inequalities in post-Soviet countries. For example, Jakobi (2011) used global and local indices of spatial autocorrelation to determine the changes in spatial patterns of the level of personal income and the unemployment rate in Hungary. Similarly, Wolny-Dominiak - Zeug-Żebro (2012) carried out spatial dependences analysis of budget incomes of counties in Poland. Within this concept, spatial autocorrelation has also been used to quantify the structures and patterns in other georeferenced economic data (see Voss et al. 2006; Tselios 2008; Chaikaew et al. 2009; Rusche 2010).

Measures of spatial autocorrelation may be either global or local. Global measures characterise the nature of spatial autocorrelation for the entire study area using one value that summarises average trends (Nelson - Boots 2008). In the context of local autocorrelation, there are two main statistics under discussion: Gi and Gi* statistics (Getis - Ord 1992; Ord - Getis 1995) and Local Moran 
(Anselin 1995). This paper concentrates on the Gi* statistics as it focuses on the significant clustering of high values ("hot spots") or low values ("cold spots").

The interrelationship between inequality and growth is particularly important for transition countries (Hölscher - Bachan 2002), therefore, as an example of the spatial autocorrelation analysis of earnings inequality we have chosen Serbia, as a country that recently underwent a dynamic economic transition. In the past decade, Serbia has undergone a very rapid change from a centralised to a market-based economy. As in other Eastern European countries, economic policies before the transition led to repressed inequalities in wages. Starting with the transition, wage patterns were replaced by entrepreneurial and market-based returns with limited state interventions (Förster et al. 2005). Furthermore, the high rate of failed privatisations of state-owned enterprises and the concentration of new investments predominantly in the Belgrade region are believed to have accentuated these regional disequilibria. ${ }^{1}$

In this research, we had two goals. The first goal was to analyse whether the spatial segregation between municipalities with high and with low net earnings increased or decreased over a 10-year time period, between 2001 (the beginning of the economic transition) and 2010 . We analysed the intensity of spatial clustering on municipalities by the average monthly net earnings, that is, the changes in the intensity of clustering over time. For this kind of global spatial autocorrelation we used Moran's I statistics. The second goal was to identify the areas where high values of net earnings cluster together (hot spots) and the areas where low values cluster together (cold spots), and how they change over time. For this kind of local spatial autocorrelation we used Getis-Ord Gi* statistics.

The contribution of this paper is twofold. First, to extend the existing research using a methodological framework within which spatial changes of net earnings can be studied with respect to statistically significant global and local spatial associations in the variables; second, to raise awareness of the increase of spatial segregation of net earnings pertaining to the Serbian labour market.

The paper is organised as follows. After the introduction, we shortly analyse the evolution of Serbia's transition economy and earnings. This is followed by an explanation of the research methodology. The next section presents maps with the main findings. Finally, the conclusion, implication, and limitation of the study are discussed.

Serbia $\left(88,361 \mathrm{~km}^{2}\right)$ has two autonomous provinces: Vojvodina $\left(21,506 \mathrm{~km}^{2}\right)$ in the north and Kosovo and Metohija $\left(10,887 \mathrm{~km}^{2}\right)$ in the south. The area that lies between Vojvodina and Kosovo and Metohija is called Central Serbia. Serbia is divided into 29 administrative districts, 150 municipalities and 24 cities (22 are city municipalities). Of the 150 municipalities, 83 are located in Central Serbia, 39 in Vojvodina and 28 in Kosovo and Metohija. Of the 24 cities, 17 are in Central Serbia, 6 are in Vojvodina and 1 in Kosovo and Metohija (Statistical Office of the Republic of Serbia 2011). 


\section{RESEARCH METHODS}

\subsection{Study area}

Serbia's economy had a favourable position in the late 1980s. Unlike many transition economies, Serbia had experience with mixed forms of ownership prior to the 1990s. The private sector was already strong in some limited areas such as agricultural production and, later, small and medium-sized enterprises (Hadžić 2002). The country's economy was gravely impacted by the war and by the economic sanctions from 1992-1995, as well as during the 1999 NATO bombing. In January 2001, the Serbian government launched a sweeping reform program aimed at accelerating the transition to a market economy (Krstić - Sanfey 2011). The significant economic reforms were made in the budgetary, fiscal and banking system (Brunhart - Gajić 2005), and the process of intensive privatisation started.

The stabilisation policy was based on a tight fiscal policy supported by concessional financing from the international financial institutions, debt rescheduling by international banks, and a borrowing arrangement with the IMF (Bartlett 2007/2008). The governmental program allowed $70 \%$ of enterprise equity to be offered to strategic investors (Lokshin - Jovanovic 2003). Structural reforms have been more successful, as the privatisation process after 2001 precipitated considerable changes in the ownership structure of the Serbian economy (Cerović - Dragutinović Mitrović 2007). Enterprise restructuring has led to a significant increase in the share of employment in private enterprises. However, the most profitable enterprises were privatised first, and their workers have enjoyed rapidly

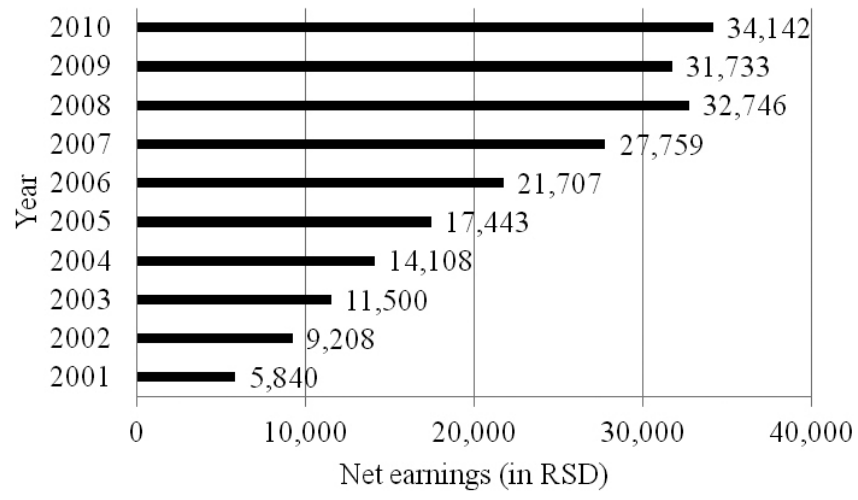

Figure 1. Average monthly net earnings (after taxes)

Source: Statistical Office of the Republic of Serbia. 
Table 1

Index of real wages and salaries (index of nominal wages and salaries divided by the consumer price index $)(2000=100)$

\begin{tabular}{ll}
\hline Year & Index \\
\hline 2001 & 118.35 \\
2002 & 154.86 \\
2003 & 176.53 \\
2004 & 196.08 \\
2005 & 209.45 \\
2006 & 233.30 \\
2007 & 266.10 \\
2008 & 275.70 \\
2009 & $275.59^{*}$ \\
2010 & 277.35 \\
\hline
\end{tabular}

Source: Eurostat (online data code: cpc_pslm).

*break in the time-series

increasing real wages (Bartlett 2007/2008). Some of the remaining sociallyowned and state-owned enterprises were making large losses, and were supported by subsidies.

The average net earnings in Serbia are among the lowest in Europe. Figure 1 gives an overview about the average monthly net earnings after taxation in the period of 2001-2010. In this period, the average monthly net salary has grown by almost 600 per cent in nominal terms; however, the average monthly net earnings in 2010 were only about 360 Euros. Furthermore, in Table 1 indexed figures on real wages and salaries (in terms of Euro) are deflated using the consumer price index. In real terms, Serbia recorded a rise of $177.35 \%$ in wages and salaries between 2000 and 2010.

The study of Lokshin - Jovanovic (2003) on wage differentials and employment decisions in the state and private sector already pointed out some significant overall regional differences. Krstić - Sanfey (2011) showed that the location and region effects on earnings were highly significant in Serbia between 2002 and 2007. Residing in urban areas provides premium relative to residing in a town, whereas employees in Belgrade and Vojvodina (northern part of Serbia) enjoy significant wages relative to those living in Central Serbia. 


\subsection{Data collection and management}

The strength of spatial relations and the interpretability of economic indicators are influenced by the choice of spatial aggregation level for administrative units. Due mainly to the availability of data, administratively defined regions are commonly used in empirical analyses (Magrini 2004). With respect to the data on average monthly net earnings, the aggregation level of municipalities and cities turns out to be appropriate for this analysis. Therefore, we used 160 polygons of municipalities and cities, i.e. the units of the administrative division of Serbia without territory of Kosovo and Metohija.

Data on average monthly net earnings were collected for every municipality and city from 2001 to 2010. The Statistical Office calculates average salaries and wages by dividing the total amount of salaries and wages paid in a referent month by the number of employees at the end of the referent month, according to personnel records. Data on average salaries and wages relate to all employees that worked in the referent month, regardless of whether or not they were paid for that work in the referent month. Net earnings present gross salaries and wages without tax and contributions.

Using a Microsoft Excel spreadsheet, we joined net earnings data (attributes) to features (municipalities) provided as polygon in a shapefile. These data are analysed using ESRI's ArcGIS software. Two ArcGIS tools are used: Spatial Autocorrelation (Global Moran's I) and Hot Spot Analysis (Getis-Ord Gi*) as a local measure. As mentioned before, there have been different proposals for local measures. For example, Local Moran statistics could be useful for indicating local deviations from the global pattern of spatial association or for identifying "hot spots". These are given by significant local clusters in the absence of global autocorrelation, or significant local outliers (Srucca 2005). However, the authors used local Getis-Ord Gi* statistics as the main research question focused on the locations of main hot spots.

\subsection{Global autocorrelation (Moran's $I$ )}

The Moran's $I$ is a measure of spatial autocorrelation developed by Moran (1950) and is used as the measure of global spatial autocorrelation. The Spatial Autocorrelation (Global Moran's $I$ ) ESRI's ArcGIS tool measures spatial autocorrelation based on both feature locations and feature values simultaneously. Given a set of features (in this case, municipalities and cities) and an associated attribute (in this case, net earnings), it evaluates whether the pattern expressed is clustered, dispersed, or random. 
ESRI (2009a) calculates the Moran's I statistics for global spatial autocorrelation as:

$$
I=\frac{n}{S_{0}} \frac{\Sigma_{i=1}^{n} \Sigma_{j=1}^{n} w_{i, j} z_{i} z_{j}}{\Sigma_{i=1}^{n} z_{i}^{2}}
$$

were $z_{i}$ is the deviation of net earnings (attribute) for municipalities and cities (feature) $i$ from its mean $\left(x_{i}-\bar{X}\right), w_{i, j}$ is the spatial weight between feature $i$ and $j$, $n$ is equal to the total number of municipalities, and $S_{0}$ is the aggregate of all the spatial weights:

$$
S_{0}=\Sigma_{i=1}^{n} \Sigma_{j=1}^{n} w_{i, j}
$$

The $z_{I}$-score for the statistics is computed as:

$$
z_{I}=\frac{I-\mathrm{E}[I]}{\sqrt{V[I]}}
$$

where:

$$
\begin{gathered}
\mathrm{E}[/]=-1 /(n-1) \\
V[I]=E\left[I^{2}\right]-E[I]^{2} \\
E\left[I^{2}\right]=\frac{(A-B)}{C} \\
A=n\left[\left(n^{2}-3 n+3\right) S_{1}-n S_{2}+3 S_{0}^{2}\right] \\
B=D\left[\left(n^{2}-n\right) S_{1}-2 n S_{2}+6 S_{0}^{2}\right] \\
C=(n-1)(n-2)(n-3) S_{0}^{2} \\
D=\frac{\sum_{i=1}^{n} Z_{i}^{4}}{\left(\sum_{i=1}^{n} Z_{i}^{2}\right)^{2}} \\
S_{1}=\left(\frac{1}{2}\right) \sum_{i=1}^{n} \sum_{j=1}^{n}\left(w_{i, j}+w_{j, i}\right)^{2} \\
S_{2}=\sum_{i=1}^{n}\left(\sum_{j=1}^{n} v_{i, j}+\sum_{j=1}^{n} w_{j, i}\right)^{2}
\end{gathered}
$$


The tool calculates the Moran's $I$ index value and $z$-score and $p$-value to evaluate the significance of the index value. A high positive $z$-score for a feature indicates that the surrounding features have similar values. A low negative $z$-score indicates that the feature is surrounded by dissimilar values (Lwin - Murayama 2009). Irrespective of whether the $z$-score is high positive or high negative, small $p$-values indicate that it is very unlikely that the observed spatial pattern is the result of random processes (ESRI 2009a).

\subsection{Hot spot analysis (Getis-Ord Gi*)}

The local Getis statistics only consider positive spatial autocorrelation and enables differentiation between clusters of similar values that are high or low relative to the mean (Getis - Ord 1992).

ESRI (2009b) calculates the Getis-Ord local statistics as:

$$
G_{i}^{*}=\frac{\Sigma_{j=1}^{n} w_{i, j} x_{j}-\bar{X} \sum_{j=1}^{n} w_{i, j}}{S \sqrt{\frac{\left[n \sum_{j=1}^{n} w_{i, j}^{2}-\left(\Sigma_{j=1}^{n} w_{i, j}\right)^{2}\right]}{n-1}}}
$$

where $x_{j}$ is the net earnings value for municipality (feature) $j, w_{i, j}$ is the spatial weight between features $i$ and $j, n$ is equal to the total number of municipalities and:

$$
\begin{gathered}
\bar{X}=\frac{\sum_{j=1}^{n} x_{j}}{n} \\
S=\sqrt{\frac{\sum_{j=1}^{n} x_{j}^{2}}{n}-(X)^{2}}
\end{gathered}
$$

The Getis-Ord local statistics returned for each feature in the dataset is a $z$ score. The $z$-score represents the statistical significance of clustering or hot spots identified by the $\mathrm{Gi}^{*}$ statistics. A high positive $z$-score for a feature indicates there is an apparent concentration of high density values within its neighbourhood of a certain distance (hot spot), and vice versa. A $z$-score near zero indicates no apparent concentration. To determine if the $z$-score is statistically significant, it was compared to the range of values for a particular confidence level. For example, at a significance level of 0.01 ( $p$-value), a $z$-score would have to be less than -2.58 or greater than 2.58 to be statistically significant (ESRI 2009b). In this analysis, features with a $z$-score greater than 2.58 were identified as hot spots at a sig- 
nificance level of 0.01 . The municipalities with a $z$-score of less than -2.58 at a significance level of 0.01 are clusters of low values (cold spot).

The strength of spatial autocorrelation is often a function of scale or spatial resolution (Gangodagamage et al. 2008). There are several ways to define spatial neighbourhoods. Choosing a distance band could be appropriate when data sites are regularly spaced and there is a conceptual reason to select a particular distance (Nelson - Boots 2008). By using fix distance metrics, we wanted to ensure a consistent scale of analysis across the entire country and overcome variations in municipality sizes. The minimum distance of $49.5 \mathrm{~km}$ was used to ensure that every polygon has at least one neighbour and to reflect the level of municipalities and cities. The distance band of $270 \mathrm{~km}$, that exhibited maximum clustering in the first three years of the investigated period, is used to highlight the broad regional trend of net earnings patterns.

\section{RESULTS}

The results of the calculation of global autocorrelation statistics for average monthly net earnings in Serbia's municipalities from 2001 to 2010 are summarised in Table 2. The results of the global Moran's tests for all years are statistically significant ( $z$-score greater than 2.58 ) and indicate the clustered patterns. As $p$-values are much less than 0.01 , clustered patterns are statistically significant.

Table 2

Global Moran's $I$ and $z$-scores from 2001 to 2010 (at a distance threshold of $49.5 \mathrm{~km}$ )

\begin{tabular}{lcrl}
\hline Year & $\begin{array}{c}\text { Global Moran's } \\
\text { Index }\end{array}$ & $z$-score & $p$-value \\
\hline 2001 & 0.230636 & 6.021961 & 0.000000 \\
2002 & 0.298522 & 7.727732 & 0.000000 \\
2003 & 0.370686 & 9.545719 & 0.000000 \\
2004 & 0.410746 & 10.582771 & 0.000000 \\
2005 & 0.490281 & 12.577104 & 0.000000 \\
2006 & 0.552704 & 14.187379 & 0.000000 \\
2007 & 0.582757 & 14.935434 & 0.000000 \\
2008 & 0.579217 & 14.860181 & 0.000000 \\
2009 & 0.533056 & 13.724154 & 0.000000 \\
2010 & 0.505702 & 13.034369 & 0.000000 \\
\hline
\end{tabular}




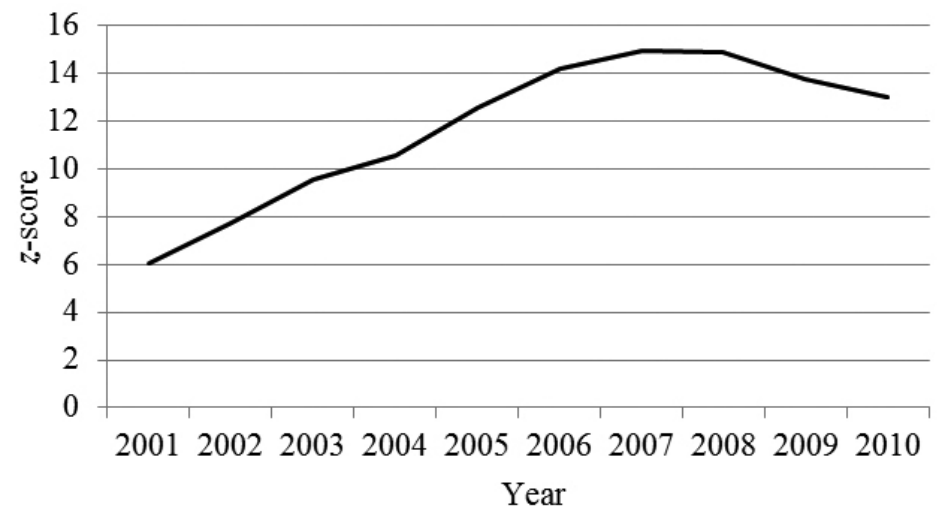

Figure 2. Z-scores for the study area

In Figure 2, the $z$-score is plotted at line graph for each year. The figure shows that $z$-score is getting bigger each year until the 2007 and after that goes slightly down. As $z$-scores are getting bigger, they are farther and farther away from the mean, meaning that municipalities are becoming more clustered.

The spatial clusters (hot and cold spots) as obtained from the local Gi* statistics for all of Serbia's municipalities by the average monthly net earnings for the period from 2001 to 2010 are shown in Figures 3 and 4. The $z$-score outcomes as calculated by the $\mathrm{Gi}^{*}$ statistics are categorised as hot or cold spots, at the $1 \%$ significance level.

Figure 3 shows broad state trends of spatial clustering of municipalities with high and low values of net earnings for a fix distance band of $270 \mathrm{~km}$. Figure 4 shows the local spatial clustering of municipalities with high and low values of net earnings for the fix distance band of $49.5 \mathrm{~km}$ (the distance that ensures every municipality has at least one neighbour). The hot spots, which are shown in black, mean statistically significant clusterings of municipalities with high net earnings, and the cold spots, marked with a framed hatch symbol, represent statistically significant clusterings of municipalities with low net earnings.

\section{DISCUSSION AND CONCLUSIONS}

In the sense of global autocorrelation, Moran's $I$ statistics clearly indicates the existence of significant spatial clustering, that is, there are significant clustering tendencies of municipalities with high average monthly net earnings and of those with low average monthly net earnings. Furthermore, the changes of $z$-scores, as 

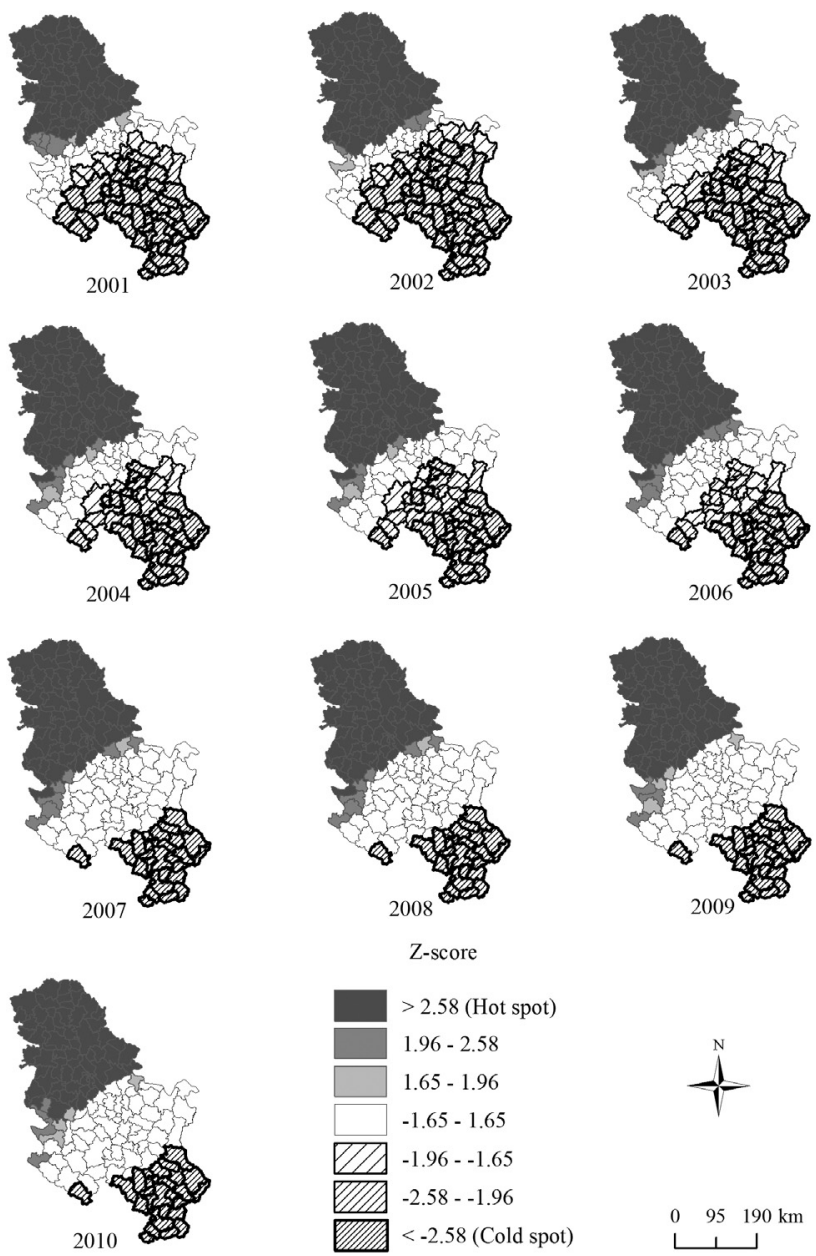

Figure 3. Spatial clusters (hot and cold spots) of the municipalities in Serbia by the level of average monthly net earnings from 2001 to 2010 (at fix distance of $270 \mathrm{~km}$ )

a measure of the intensity of spatial clustering, suggest that clustering increased over time. The $z$-score was increasing until 2007. A small decline was reported in the last three years of the study period. Still, it was more than twice as high as in 2001. This allows us to conclude that overall segregation between municipalities with high and low average monthly net earnings was predominantly increasing.

The results of local statistics as obtained from the hot spot analysis for the 270 $\mathrm{km}$ distance band reveal a clear north-south division of net earnings. There are 


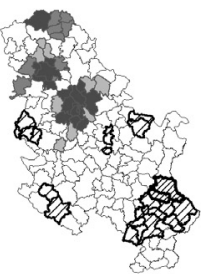

2001
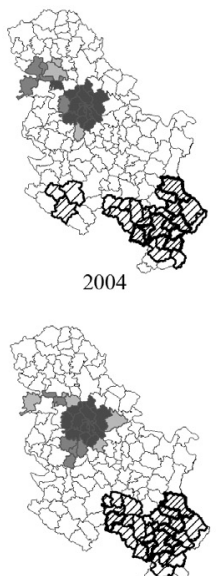

2007

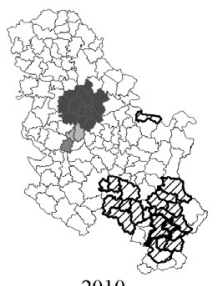

2010

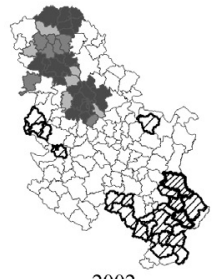

2002

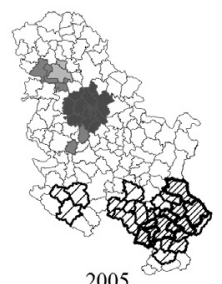

2005

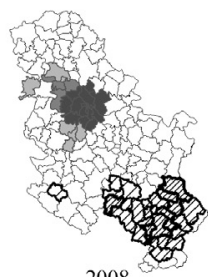

2008

Z-score

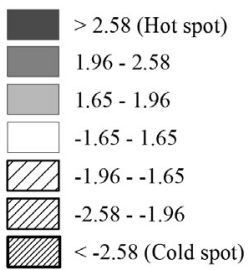

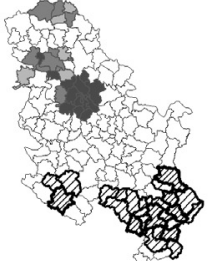

2003
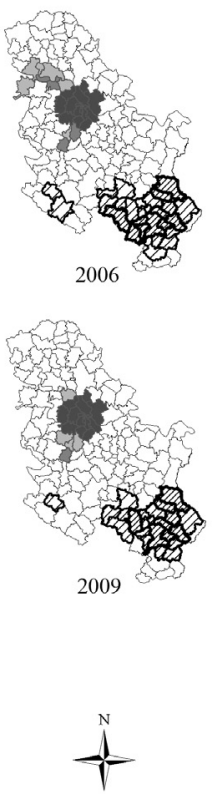

$0 \quad 95190 \mathrm{~km}$

Figure 4. Spatial clusters (hot and cold spots) of the municipalities in Serbia by the level of average monthly net earnings (at a fix distance of $49.5 \mathrm{~km}$ )

broad state trends of the spatial clustering of municipalities with high net earnings in the north and of low net earnings in the south. From 2001 to 2010, the spatial segregation between hot and cold spots increased. The cold spot narrows as spatial clustering is becoming more random in the central parts of the country. Looking at the results of the hot spot analysis at a smaller scale $(49.5 \mathrm{~km})$ reveals more localised clustering. At the beginning of the study period (the beginning of the economic transition), there were three statistically significant hot spots in the 
north, located around three big cities: Belgrade, Novi Sad, and Subotica. As time passed, only one highly clustered hot spot remained: the Belgrade region. Of the two cold spots in the south, only one remained relatively still positioned in the country's southeast.

The evidence presented in this study could be linked to some findings (Bartlett et al. 2013) that spatial inequalities seem to have widened in many post-socialist economies during the transition period. More precisely, as the market is opening, spatial adjustments under transition favour metropolitan regions (Petrakos 2010). The most important results of this study correspond with the work of Monastiriotis (2013): while researching the extent and scale of spatial disparities in Serbia from 1995 to 2008, he identified substantial north-south polarisation, that seems to be deepening, even though this has not resulted in a widening of overall spatial disparities. He finds that spatial disparities in Serbia seem to be much more of a macro-geographical phenomenon than a localised core-periphery pattern, mostly because of the cluster around the capital city of Belgrade and the rest of the country. Furthermore, a trend of declining of clusters outside the central city-region was also identified in Monastiriotis' study.

As an important segment of spatial analysis, spatial autocorrelation can provide an important insight into the pattern of the distribution of earnings across state territories. However, it should be noted that global measures of spatial autocorrelation should be presented when local measures are calculated, and when significant global spatial autocorrelation exists, the likelihood of falsely identifying significant local spatial autocorrelation increases (Ord - Getis 2001).

The authors used $\mathrm{Gi}^{*}$ statistics as a measure of local autocorrelation, although it has been developed for data sets in which there is no global spatial autocorrelation. However, the research question focusing on the determination of the overall change of placement of hot and cold spots could be answered by using this measurement.

Understanding where the statistically significant hot and cold spots are and how they change over time can strengthen the ability of policy makers to address spatial inequality problems. Policy makers can reach better decisions to deal with problems of spatial inequality as a special insight can help to determine persistent clusters of municipalities where additional measures should be focused. This is of great importance in the case of clusters of small average net earnings municipalities in the southern part of the country. However, some broader based measure of well-being should be calculated and mapped for precise decision-making. Still, determined patterns and hot and cold spots are statistically significant, and therefore should be investigated further. 


\section{REFERENCES}

Anselin, L. (1995): Local Indicators of Spatial Association - LISA. Geographical Analysis, 27(2): 93-115.

Bartlett, W. (2007/2008): Economic Transition in Serbia since 2000: Trends and Prospects. Western Balkans Security Observer, 7-8: 29-37.

Brunhart, R. - Gajić, N. (2005): Policing the Economic Transition in Serbia: Assessment of the Serbian Police Service's Capacities to Fight Economic Crime. Belgrade: OSCE Mission to Serbia and Montenegro.

Burt, J. E. - Barber, G. M. - Rigby, D. L. (2009): Elementary Statistics for Geographers. New York: The Guilford Press.

Cerović, B. - Dragutinović Mitrović, R. (2007): Privatisation Effects: Some Evidence from Serbia. Transition Studies Review, 14(3): 469-487.

Chaikaew, N. - Tripathi, N. T. - Souris, M. (2009): Exploring Spatial Patterns and Hotspots of Diarrhea in Chiang Mai, Thailand. International Journal of Health Geographic, 8(1): 36.

Förster, M. - Jesuit, D. - Smeeding, T. (2005): Regional Poverty and Income Inequality in Central and Eastern Europe: Evidence from the Luxembourg Income Study. In: Kanbur, R. - Venables, A. J. (eds): Spatial Inequality and Development. Oxford: Oxford University Press, pp. 313347.

ESRI (2009a): How Spatial Autocorrelation: Moran's I (Spatial Statistics) Works (available at: http://webhelp.esri.com/arcgisdesktop/9.3/index.cfm?TopicName=How\%20Spatial\%20Autocorrelation:\%20Moran\%27s\%20I\%20(Spatial\%20Statistics)\%20works).

ESRI (2009b): How Hot Spot Analysis: Getis-Ord Gi* (Spatial Statistics) Works (available at: http://webhelp.esri.com/arcgisdesktop/9.3/index.cfm?TopicName=How\%20Hot $\% 20$ Spot $\% 20$ Analysis:\%20Getis-Ord\%20Gi*\%20(Spatial\%20Statistics)\%20works).

Gangodagamage, C. - Zhou, X. - Lin, H. (2008): Autocorrelation, Spatial. In: Shekar, S. - Xiong, H. (eds): Encyclopedia of GIS. New York: Springer, pp. 32-37.

Getis, A. - Ord, J. K. (1992): The Analysis of Spatial Association by Use of Distance Statistics. Geographical Analysis, 24(3): 189-206.

Hadžić, M. (2002): Rethinking Privatization in Serbia. Eastern European Economics, 40(6): 6-23.

Hölscher, J. - Bachan, R. (2002): Income Dynamics and Stability in the Transition Process. Acta Oeconomica, 52(4): 421-442.

Jakobi, A. (2011): Examining Neighbourhood Effects in Regional Inequalities of Hungary: A GISBased Approach from Topological Relations to Neighborhood Heterogeneity. Romanian Review of Regional Studies: Journal of the Centre for Regional Geography, 7(1): 53-62.

Krstić, G. - Sanfey, P. (2011): Earnings Inequality and the Informal Economy: Evidence from Serbia. Economics of Transition, 19(1): 179-199.

Lokshin, M. M. - Jovanovic, B. (2003): Wage Differentials and State - Private Sector Employment Choice in Yugoslavia. Economics of Transition, 11(3): 463-491.

Lwin, K. - Murayama, Y. (2009): A GIS Approach to Estimation of Building Population for MicroSpatial Analysis. Transactions in GIS, 13(4): 401-414.

Magrini, S. (2004): Regional (Di)convergence. In: Henderson, J. V. - Thiesse, J. F. (eds): Handbook of Regional and Urban Economics, vol. 4. Amsterdam: Elsevier, pp. 2741-2796.

Monastiriotis, V. (2013): The Nature of Spatial Inequalities in South East Europe and the Scope for Decentralized Regional Policy. An Analysis of Bulgaria and Serbia. In: Bartlett, W. - Maleković, S. - Monastiriotis, V. (eds): Decentralization and Local Development in South East Europe. Basingstoke: Palgrave Macmillan, pp. 213-230.

Moran, P. A. P. (1950): Notes on Continuous Stochastic Phenomena. Biometrika, 37(1): 17-23. 
Nelson, T. A. - Boots, B. (2008): Detecting Spatial Hot Spots in Landscape Ecology. Ecography, 31(5): 556-566.

Ord, J. K. - Getis, A. (1995): Local Spatial Autocorrelation Statistics: Distributional Issues and an Application. Geographical Analysis, 27(4): 286-306.

Ord, J. K. - Getis, A. (2001): Testing for Local Spatial Autocorrelation in the Presence of Global Autocorrelation. Journal of Regional Science, 41(3): 411-432.

Patacchini, E. - Rice, P. (2007): Geography and Economic Performance: Exploratory Spatial Data Analysis for Great Britain. Regional Studies, 41(4): 489-508.

Petrakos, G. (2001): Patterns of Regional Inequality in Transition Economies. European Planning Studies, 9(3): 359-383.

Rey, S. J. - Montouri, B. D. (1999): US Regional Income Convergence: A Spatial Econometric Perspective. Regional Studies, 33(2): 143-156.

Rusche, K. (2010): Quality of Life in the Regions: An Exploratory Spatial Data Analysis for West German Labour Market. Jahrbuch für Regionalwissenschaft, 30: 1-22.

Srucca, L. (2005): Clustering Multivariate Spatial Data Based on Local Measures of Spatial Autocorrelation. An Application to the Labour Market of Umbria. St. Louis, Ideas (available at http:// www.ec.unipg.it/DEFS/uploads/spatcluster.pdf).

Stanovnik, T. - Verbič, M. (2013): Earnings Inequality and Tax Progressivity in Slovenia, 19912009. Acta Oeconomica, 63(4): 405-421.

Statistical Office of the Republic of Serbia (2011): Statistical Pocketbook of the Republic of Serbia. Belgrade.

Statistical Office of the Republic of Serbia (several years): Municipalities and Regions in the Republic of Serbia. Belgrade.

Thomas, R. W. - Huggett, R. J. (1980): Modelling in Geography: A Mathematical Approach. New Jersey: Barnes \& Noble Books.

Tselios, V. (2008): Income and Educational Inequalities in the Regions of the European Union: Geographical Spillovers under Welfare State Restrictions. Papers in Regional Science, 87(3): 403-430.

Voss, P. R. - Long, D. - Hammer, R. (2006): County Child Poverty Rates in the US: A Spatial Regression Approach. Population Research and Policy Review, 25: 369-391.

Wolny-Dominiak, A. - Zeug-Żebro, K. (2012): Spatial Statistics in the Analysis of County Budget Incomes in Poland with the R CRAN. Proceedings of 30th International Conference Mathematical Methods in Economics, Karviná, Czech Republic, pp. 992-997.

Zierahn, U. (2012): The Importance of Spatial Autocorrelation for Regional Employment Growth in Germany. Jahrbuch für Regionalwissenschaft, 32: 19-43. 